\title{
Effect of Culture Technique on the Work Up in cirrhotic Patients with Spontaneous Bacterial Peritonitis
}

\author{
Usama Ahmed Arafa', Mahmoud Kamal El Samman', Laila Mohammed Yousef ${ }^{2,}$ \\ Abdalla Rashad Mohammed ${ }^{1}$, Ali Mahmoud Ahmed Kassem"
}

\section{1- Internal Medicine Department, Sohag Faculty of Medicine ,Sohag University.}

2- Clinical Pathology Department, Sohag Faculty of Medicine, Sohag university.

Background: Spontaneous bacterial peritonitis (SBP) is a serious complication in patients with advance liver cirrhosis and is associated with significant mortality. Multidrug resistance is an evolving problem in management of SBP. Therefore, early diagnosis and proper selection of antimicrobial therapy are warranted.

Objective: Assessment of the accuracy of conventional culture compared to blood culture in diagnosis of SBP and evaluation the role of blood culture in selection of antimicrobial therapy for treatment of SBP.

Methods: One hundred unselected consecutive cirrhotic patients with moderate or severe ascitis who were admitted to Internal Medicine Department during the period from October 2016 to April 2017 were included. Diagnostic aspiration of the ascetic fluid was made for each patient. The aspirated samples underwent chemical and cytological analysis as well as inoculation on conventional culture and on blood culture. Positive growths were tested for antibiotic sensitivity.

Results: 47 patients (47\%) among the 100 cirrhotic patients had spontaneous bacterial peritonitis. Positive growths were detected in 11 patients $(23.4 \%)$ and in $32(68.1 \%)$ patients by using conventional culture and blood culture respectively. By using blood culture as gold stander, the sensitivity, specificity, positive predictive value and negative predictive value of conventional culture were $34.38 \%, 100 \%, 100 \%$ and $41.67 \%$ respectively. All isolated growths were sensitive to meropenem. Resistance to cefotaxime was detected in 20 cases $(62.5 \%)$. Other tested drugs showed variable degrees of sensitivity.

Conclusion: Conventional culture is of low sensitivity in diagnosis of SBP among cirrhotic patients and blood culture should be considered the gold standard for diagnosis of SBP. Multidrug resistance in SBP is common and antibiotic selection should be based on culture and sensitivity tests.

Key words: Spontaneous Bacterial Peritonitis, Blood Culture, Multidrug resistance.

\section{Introduction:}

Spontaneous bacterial peritonitis (SBP) is a serious infection caused by bacteria in cirrhotic patients and is associated with significant high mortality (1). There are various clinical local and/or systemic signs for SBP, ranging from local abdominal features of peritoneal inflammation with or without manifestations of systemic inflammation to impaired renal function without explanation (2). Early diagnosis and proper management of SBP have an important role in reduction of the morbidity and mortality that are associated with this serious infection in patients with advanced liver disease.
Ascitic fluid culture has an important role in the diagnosis and management of SBP. Conventional bacterial culture methods effectively detect bacteria in less than $50 \%$ of ascites samples with an elevated PMN count $(>250 / \mathrm{mm})$. The culturepositive rate of SBP is approximately $80 \%$ of cases assessed using the culture bottle method (3). Therefore, inoculation of the ascitic fluid into blood culture bottles at the patient's bedside is expected to increase the sensitivity of the bacterial culture.

Cefotaxime, a third-generation cephalosporin, was considered to be the drug of choice in treatment of SBP with a dose of $4 \mathrm{~g} /$ day for at least 5 
SOHAG MEDICAL JOURNAL

Vol. 21 No.3 october 2017
Effect of Culture Technique on the Work Up

Abdalla Rashad Mohammed1 days, this dose achieves high ascitic fluid concentrations and covers most of the causative organisms (4). Intestinal decontamination can also be achieved by other antibiotics. However, the extensive long-term use of these drugs lead to increased incidence of drug resistance and emergence of SBP caused by Grampositive organisms (5). The emergence of resistant to bacteria gives the challenges in SBP treatment. Therefore, appropriate selection of antibiotic therapy for SBP is mandatory.

The aim of the study was to assess the use of conventional and blood cultures in management of SBP in patients with liver cirrhosis and their role in selection of the appropriate antibiotic therapy for treatment of SBP.

\section{Materials and Methods:}

The study was a prospective study that was conducted on cirrhotic patients who were admitted in Internal Medicine Department, Faculty of Medicine, Sohag University, during period from October 2016 to April 2017 and fulfilled the inclusion criteria. The study included cirrhotic patients with moderate or tense ascites, aged $>18$ years, who accepted participation in this study. The exclusion criteria included presence definite alternative diagnosis for ascites, septic peritonitis, patients with burst abdomen or recent abdominal trauma and those who received antibiotic within 3 days before performing diagnostic paracentesis.

Diagnosis of liver cirrhosis was based upon clinical evaluation, liver function tests, abdominal ultrasonography, and hepatitis markers or Polymerase Chain Reaction (PCR). Diagnosis of SBP was conducted according to international guidelines if the polymorphonuclear leukocyte (PMN) cell count in the ascetic fluid exceeded $250 / \mathrm{ml}$ in the absence of source of intra-abdominal infection (6).

Clinical evaluation for all patients was done, including full history and clinical examination. Laboratory investigation included the following: Complete blood count (CBC) test was performed on Cell Dyn 3700 automated cell counter ,Abbott diagnostic. kidney function tests and liver function tests were done by Roche/Hitachi Coabas C311 system. Prothrombin time and concentration, inter-national normalization ratio (DadeBehring, Marburg, Germany kit). Blood culture of aspired fluid on Bact/ALERT SA Biomerieux. Under aseptic condition, diagnostic aspiration of the ascetic fluid was performed at the time of admission. The collected ascetic fluids were analysis (cells, protein and glucose) and inoculated on both conventional and blood culture. The isolated bacteria was tested for antimicrobial sensitivity. Each patient assigned a written informed consent and the study protocol was approved from our university ethics committee.

\section{Statistical analysis:}

Data was analyzed using STATA intercooled version 12.1. Data expressed as mean, standard deviation (SD), number and percentage. Mean and standard deviation were used as descriptive value for quantitative data. Chi square test was used for qualitative data. $\mathrm{P}$ value was considered significant if it was less than 0.05. When the data was not normally distributed Mann-Whitney test was used. 
SOHAG MEDICAL JOURNAL

Vol. 21 No.3 october 2017
Effect of Culture Technique on the Work Up

Abdalla Rashad Mohammed1

\section{Results:}

Clinical characteristic of the patients: The study involved 100 cirrhotic patient including54 (54\%) male and 46(46\%) female with mean age 62.02 \pm 10.32 and range (30-86) year. The etiology of liver cirrhosis was $\mathrm{HBV}$ in $7(7 \%)$ patient, $\mathrm{HCV}$ in $42(42 \%)$ patient and the remaining $51(51 \%)$ patients were negative for $\mathrm{HCV}$ and $\mathrm{HBV}$. Child Pugh score was Child B in 57(57\%) patient and Child C in 43(43\%) patient. Model For End-Stage Liver Disease (MELD score) mean was 12.71 \pm 2.9 and range (10-18). 84(84\%)patient were presented by fever, and84 (84\%)were presented by abdominal pain. Among included patients, 47 (47\%) patients had SBP as shown in Table 1.

Conventional and blood cultures:

Among patients with SBP, blood culture of ascetic fluid showed positive growth in 32 case $(68.08 \%)$ case and culture-negative neutrocytic ascites was detected in 15(31.9\%) case. While, conventional culture revealed positive growth in $11(23.4 \%)$ case and it was negative in $36(76.6 \%$ ) case. Compared to blood culture, conventional culture showed low sensitivity for diagnosis of SBP as shown in Table 2. Antimicrobial culture sensitivity was assessed using 15 drugs that suspected to be effective in treatment of SBP. Among these drugs, only meropenem showed sensitivity in all isolated growth. Cefotaxime, commonly used in treatment of SBP, showed intermediate antimicrobial sensitivity in $12(37.5 \%)$ case and resistance in $20(62.5 \%)$ case. Other examined drugs showed variable degrees of efficacy as shown in Table 3.

Table 1- Clinical data of all patients and patients with SBP

\begin{tabular}{|c|c|c|}
\hline Variables & $\begin{array}{l}\text { All patients } \\
(\mathrm{N}=\mathbf{1 0 0})\end{array}$ & $\begin{array}{l}\text { Patients with } \\
\text { SBP }(N=47)\end{array}$ \\
\hline $\begin{array}{l}\text { Age } \\
\text { Mean } \pm \text { SD / Median } \\
\text { (range) }\end{array}$ & $\begin{array}{l}62.02 \pm 10.32 / \\
61(30-86)\end{array}$ & $\begin{array}{l}60.96 \pm 9.94 / \\
60(40-85)\end{array}$ \\
\hline $\begin{array}{l}\text { Gender } \\
\text { Females / Males }\end{array}$ & $\begin{array}{l}46(46 \%) / \\
54(54 \%)\end{array}$ & $\begin{array}{l}20(42.55 \%) / \\
27(57.45 \%)\end{array}$ \\
\hline $\begin{array}{l}\text { Cause of liver } \\
\text { cirrhosis } \\
\text { HBV / HCV } \\
\text { Others }\end{array}$ & $\begin{array}{l}7(7 \%) / \\
42(42 \%) \\
51(51 \%)\end{array}$ & $\begin{array}{l}3(6.38 \%) / \\
20(42.55 \%) \\
42(51.06 \%)\end{array}$ \\
\hline $\begin{array}{l}\text { Child Pugh score } \\
\text { Child B / Child C }\end{array}$ & $\begin{array}{l}57(57 \%) / \\
43(43 \%)\end{array}$ & $\begin{array}{l}27(57.45 \%) / \\
20(42.55 \%)\end{array}$ \\
\hline $\begin{array}{l}\text { MELD score } \\
\text { Mean } \pm \text { SD / Median } \\
\text { (range) }\end{array}$ & $\begin{array}{l}21.7 \pm 2.9 / 14 \\
(10-18)\end{array}$ & $\begin{array}{l}12.6 \pm 3.06 / \\
10(10-18)\end{array}$ \\
\hline $\begin{array}{l}\text { Fever } \\
\text { No / Yes }\end{array}$ & $\begin{array}{l}16(16 \%) / \\
84(84 \%)\end{array}$ & $\begin{array}{l}9(19.15 \%) / \\
38(80.85 \%)\end{array}$ \\
\hline $\begin{array}{l}\text { Abdominal pain } \\
\text { No / Yes }\end{array}$ & $\begin{array}{l}16(16 \%) / \\
84(84 \%)\end{array}$ & $\begin{array}{l}6(12.77 \%) / \\
41(87.23 \%)\end{array}$ \\
\hline $\begin{array}{l}\text { Hepatic } \\
\text { encephalopathy } \\
\text { No / Yes }\end{array}$ & $\begin{array}{l}52(52 \%) / \\
48(48 \%)\end{array}$ & $\begin{array}{l}25(53.19 \%) / \\
22(48.81 \%)\end{array}$ \\
\hline $\begin{array}{l}\text { History of SBP } \\
\text { No / Yes }\end{array}$ & $\begin{array}{c}85(85 \%) / \\
15(15 \%)\end{array}$ & $\begin{array}{l}34(72.34 \%) / \\
13(27.66 \%)\end{array}$ \\
\hline Presence of SBP & $47(47 \%)$ & $47(100 \%)$ \\
\hline $\begin{array}{l}\text { Conventional } \\
\text { culture }\end{array}$ & $11(11 \%)$ & $11(23.4 \%)$ \\
\hline Blood culture & $32(32 \%)$ & $32(68.08 \%)$ \\
\hline
\end{tabular}

SBP, spontaneous bacterial peritonitis: HBV, hepatitis B virus; HCV, hepatitis C virus; MELD, Model for End-Stage Liver Disease; 
SOHAG MEDICAL JOURNAL

Vol. 21 No.3 october 2017
Effect of Culture Technique on the Work Up Abdalla Rashad Mohammed1

Table 2-Accuracy of conventional culture compared to blood culture:

\begin{tabular}{|l|l|c|c|c|}
\hline \multicolumn{5}{|c|}{ Blood culture } \\
\hline \multirow{3}{*}{ Conventional culture } & & Positive & Negative & Total \\
\cline { 2 - 5 } & Positive & 11 & 0 & 11 \\
\cline { 2 - 5 } & Negative & 21 & 15 & 36 \\
\cline { 2 - 5 } & Total & 32 & 15 & 47 \\
\hline Sensitivity & \multicolumn{5}{|c|}{$100 \%$} \\
\hline Specificity & \multicolumn{5}{|c|}{$100 \%$} \\
\hline Positive predictive value & $41.67 \%$ \\
\hline Negative predictive value & $4.67 \%$ \\
\hline Accuracy & $67.19 \%$ \\
\hline
\end{tabular}

Table 3 - Antibiotics sensitivity of positive bacterial growth in blood culture.

\begin{tabular}{|l|c|c|c|}
\hline \multirow{2}{*}{ Drugs } & \multicolumn{3}{|c|}{ Antimicrobial Sensitivity } \\
\cline { 2 - 4 } & Sensitive & Intermediate & Resistance \\
\hline $\begin{array}{l}\text { Amoxicillin/ } \\
\text { Clavulonic A }\end{array}$ & $10(31.25 \%)$ & $14(43.75 \%)$ & $8(25 \%)$ \\
\hline Amikacin & $18(56.25 \%)$ & $13(40.63 \%)$ & $1(3.13 \%)$ \\
\hline $\begin{array}{l}\text { Chloramphen- } \\
\text { icol }\end{array}$ & $11(34.38 \%)$ & $18(56.25 \%)$ & $3(9.38 \%)$ \\
\hline Cefotaxime & 0 & $12(37.50 \%)$ & $20(62.50 \%)$ \\
\hline Nitrofurantoin & $14(43.75 \%)$ & $18(56.25 \%)$ & 0 \\
\hline Meropenem & $32(100 \%)$ & 0 & 0 \\
\hline Neomycin & $13(40.63 \%)$ & $17(53.13 \%)$ & $2(6.25 \%)$ \\
\hline $\begin{array}{l}\text { Ampicillin / } \\
\text { Sulbactam }\end{array}$ & $17(53.13 \%)$ & $7(21.88 \%)$ & $8(25 \%)$ \\
\hline Tetracycline & $9(28.13 \%)$ & $18(56.25 \%)$ & $5(15.63 \%)$ \\
\hline Levofloxacin & $12(37.50 \%)$ & $12(37.50 \%)$ & $8(25 \%)$ \\
\hline Gentamycin & $6(18.75 \%)$ & $21(65.63 \%)$ & $5(15.63 \%)$ \\
\hline $\begin{array}{l}\text { Cefoprazole } \\
\text { /Sulbactam }\end{array}$ & $8(25 \%)$ & $15(46.88 \%)$ & $9(28.13 \%)$ \\
\hline Erythromycin & $4(12.50 \%)$ & $18(56.25 \%)$ & $10(31.25 \%)$ \\
\hline Trimethoprim & $5(15.63 \%)$ & $9(28.13 \%)$ & $18(56.25 \%)$ \\
\hline $\begin{array}{l}\text { Sulfamethox- } \\
\text { azole }\end{array}$ & $3(9.38 \%)$ & $10(31.25 \%)$ & $19(59.38 \%)$ \\
\hline Rifampicin & $2(6.25 \%)$ & $12(37.50 \%)$ & $18(56.25 \%)$ \\
\hline
\end{tabular}

Discussion:

SBP is a serious complication that occurs in patients with advanced liver disease. Small intestinal bacterial overgrowth showed high prevalence among cirrhotic patients (7) and it has been associated with the development of SBP because of the bacterial translocation of from the intestinal lumen to the ascetic fluid and the systemic circulation as well (8). In our study, SBP was detected in 47 patients including 27 patients with Child B and 20 with Child C. High incidence of SBP among our patients could be due to special attention to diagnosis SBP in our department and performing diagnostic aspiration of ascetic fluid to all cirrhotic patients with ascites upon admission. Component of ascetic fluid bacteria is correlated with the stage of 
SOHAG MEDICAL JOURNAL

Vol. 21 No.3 october 2017
Effect of Culture Technique on the Work Up

Abdalla Rashad Mohammed1 hepatic decompensation and the ChidPugh score. The relationship is proving the link between gut microbiota and progression of cirrhosis (9).

Conventional culture of aspirated ascetic fluid in our study showed low sensitivity and low diagnostic accuracy compared to the use of blood culture bottles in diagnosis of SBP. In our study, we adapted bedside inoculation of ascitic fluid into blood culture bottles to increase the culturepositivity of the aspirated ascitic fluid. The results of ascetic fluid culture are affected by several factors including the use of blood culture bottles and the volume of the ascetic fluid sample.SBP is a low-colony-count monomicrobial infection which is similar to bacteremia $(10,11,12)$. Several studies revealed that immediate inoculation of the aspirated ascitic fluid into blood culture bottles is superior to delayed inoculation in cirrhotic patients with ascitic fluid PMN count $\geq 250$ cells $/ \mathrm{mm}^{3}$ Culture positivity with immediate inoculation was reported to increase up to $80-100$ $\%$ compared to $50-77 \%$ with delayed inoculation $(13,11,12)$. Therefore, dramatic decreases in the sensitivity of the culture that can occur by sending of the aspirated fluid to the laboratory for culture should be avoided by following beside inoculation rather than delayed inoculation technique.

In our study, we inoculated $5 \mathrm{ml}$ of aspirated ascetic fluid into $30 \mathrm{ml}$ blood culture bottles. Runyon BA et al reported that inoculation of 10 or $20 \mathrm{~mL}$ of ascetic fluid into $100 \mathrm{~mL}$ blood culture bottles led to dramatic increase in culture-positivity rate than a $1 \mathrm{~mL}$ inoculum (93 versus $53 \%$ ) (10).

Culture-negative neutrocytic ascites was detected in about $30 \%$ of our cirrhotic patients with SBP and ascitic fluid PMN count $\geq 250$ cells
$/ \mathrm{mm}^{3}$. Lack of delectation bacterial growth in presence of increased PMN count in ascetic fluid could be attributed to several factors. Inappropriately parenteral antibiotic administration before perfo-rming paracentesis is not infrequent and result in reduction in the culture positivity(14).Inadequate culture technique and inadequate volume are also included in reduction of culture positivity. Moreover, one of the other causes of culture-negative neutrocytic ascites could be overlooked in our study. Therefore, proper culture technique and avoiding antibiotic administration before paracentesis and proper exclusion of other causes of increased PMN in ascetic fluid are factors that should be considered to increase bacterial growth and culture positivity.

Third-generation, broad-spectrum cephalosporins were considered to be the agents of choice for treatment of SBP due to their superiority in randomized controlled trials and rare side effect profile and low risk of nephrotoxicity compared to other antibiotics $(15,16,17)$. Cefotaxime was considered to be the drug of choice in treatment of SBP. It was reported to cover most SBP pathogens with excellent ascitic fluid penetration and it was associated with high sterilization rate (18). However, long term use of this drugs results in development of drug resistance organisms that are in need for new antibiotic or antibiotic combination to be resolved. Alternative intravenous antibiotic regimens for SBP other than third-generation cephalosporins are available but their use is associated with increased risk for adverse events and there is less evidence that support their role in primary treatment of SBP.

Our study showed poor sensitivity to several antibiotic that are frequently used in our community. Inappropriate 
SOHAG MEDICAL JOURNAL

Vol. 21 No.3 october 2017
Effect of Culture Technique on the Work Up

Abdalla Rashad Mohammed1 use of these drugs results in development of multi-drug-resistant bacteria which are expected to increase the morbidity and mortality in cirrhotic patients with SBP. Use of broad-spectrum antibiotic should be narrowed and should be based upon culture results to minimize the risk of development of antibiotic resistance. We faced some limitations in our study. Firstly, the relative limited number of included patients with SBP. Secondly, lack of assessment antimicrobial sensitivity of the recent discovered broad spectrum antibiotics like glykopeptides and carbapenems which were considered to be an effective alternative therapy in treatment of SBP $(19,20)$.Lastly, lack of follow-up of recurrence of SBP among the treated patients. However, our study is the first study in our locality which highlight the

1- Giannelli V, Di Gregorio V, Iebba $\mathrm{V}$, et al. Microbiota and the gut-liver axis: bacterial translocation, inflammation and infection in cirrhosis. World journal of gastroenterology: WJG 2014; 20:

2- Nousbaum JB, Cadranel JF, Nahon P, et al. Diagnostic accuracy of the Multistix 8 SG reagent strip in diagnosis of spontaneous bacterial peritonitis. Hepatology 2007; 45: 1275-81.

3- Runyon BA. Management of adult patients with ascites due to cirrhosis: an update. Hepatology.2009;49(6):2087-2107.

4- Rimola A, Salmerón JM, Clemente G, Rodrigo L, Obrador A, Miranda ML, et al. Two different dosages of cefotaxime in the treatment of spontaneous bacterial peritonitis in cirrhosis: results of a prospective, randomized, multicenter study. Hepatology 1995; 21: 674-9.

5- Biecker E. Diagnosis and therapy of ascites in liver cirrhosis. World journal of gastroenterology: WJG 2011; 17: 1237. importance of blood culture in treatment of SBP and proper selection of the effective antimicrobial therapy. We concluded that blood culture of ascetic fluid in cirrhotic patient has an essential role in diagnosis of SBP in while conventional culture showed low sensitivity in the diagnosis. Multidrug resistance in SPB is common especially for cefotaxime and antibiotic selection should be based on antimicrobial culture sensitivity.

Acknowledgment: The authors are grateful to all who participated in the study.

\section{Funding:}

There were no external funding corporation.

\section{Disclosure statement:}

All authors declared no conflicts of interest.

\section{References:}

6- Ginés P, Angeli P, Lenz K, Møller $\mathrm{S}$, Moore K, Moreau R. European Association for the Study of the Liver. EASL clinical practice guidelines on the management of ascites, spontaneous bacterial peritonitis, and hepatorenal syndrome in cirrhosis. J Hepatol 2010; 53.

7- Giannelli V, Di Gregorio V, Iebba V, et al. Microbiota and the gut-liver axis: bacterial translo-cation, inflammation and infection in cirrhosis. World journal of gastroenterology: WJG 2014; 20: 16795.

8- Hanouneh MA, Hanouneh IA, Hashash $\mathrm{JG}$, et al. The role of rifaximin in the primary prophylaxis of spontaneous bacterial peritonitis in patients with liver cirrhosis. Journal of clinical gastroenterology 2012; 46: 709-15.

9- Rogers GB, van der Gast CJ, Bruce KD, et al. Ascitic microbiota composition is correlated with clinical severity in cirrhosis with portal hypertension. PloS one 2013; 8: e74884.

10- Runyon BA, Canawati HN, Akriviadis EA. Optimization of ascitic fluid culture 
SOHAG MEDICAL JOURNAL

technique. Gastroenterology 1988; 95:1351.

11- Runyon BA, Antillon MR, Akriviadis EA, McHutchison JG. Bedside inoculation of blood culture bottles with ascitic fluid is superior to delayed inoculation in the detection of spontaneous bacterial peritonitis. J ClinMicrobiol 1990; 28:2811.

12- Wong CL, Holroyd-Leduc J, Thorpe KE, Straus SE. Does this patient have bacterial peritonitis or portal hypertension? How do I perform a paracentesis and analyze the results? JAMA 2008; 299:1166.

13- Such J, Runyon BA. Spontaneous bacterial peritonitis.Clin Infect Dis 1998; 27:66974.

14- Akriviadis EA, Runyon BA. Utility of an algorithm in differentiating spontaneous from secondary bacterial peritonitis. Gastroenterology 1990; 98:127.

15- Felisart J, Rimola A, Arroyo V, et al. Cefotaxime is more effective than is ampicillin-tobramycin in cirrhotics with severe infections. Hepatology 1985; 5: 457-62
16- Runyon BA, McHutchison JG, Antillon $\mathrm{MR}$, et al. Short-course vs. long-course antibiotic treatment of spontaneous bacterial peritonitis: a randomized controlled trial of 100 patients. Gastroenterology 1991; 100:1737-42.

17- Navasa M, Follo A, Llovet JM, et al. Randomized, comparative study of oral ofloxacin versus intravenous cefotaxime in spontaneous bacterial peritonitis. Gastroenterology 1996;111: 1011-7.

18- Runyon BA, Akriviadis EA, Sattler FR, et al. Ascitic fluid and serum cefotaxime and desacetylCefotaxime levels in patients treated for bacterial peritonitis. Dig Dis Sci 1991; 36:1782.

19- Jalan R, Fernandez J, Wiest R, et al. Bacterial infections in cirrhosis: a position statement based on the EASL Special Conference 2013. Journal of hepatology 2014; 60: 1310-24.

20- Fernández J, Gustot T. Management of bacterial infections in cirrhosis. Journal of hepatology 2012; 56: S1-S12. 